\title{
Long-term follow-up study on prevention of aphakic cystoid macular oedema by topical indomethacin
}

\author{
KENSAKU MIYAKE, SHIZUKO SAKAMURA, AND HANA MIURA \\ From the Shozankai Medical Foundation, Miyake Eye Clinic Hospital, Nagoya, Japan
}

SUMMARY In addition to routine medications topical indomethacin was applied to one group of 112 eyes and an appropriate placebo was applied to another group of 106 eyes that underwent intracapsular cataract extraction. The investigation was conducted in a prospective double blind fashion over a long period of time in order to demonstrate the effects of indomethacin in preventing the development of cystoid macular oedema. Indomethacin drops were instilled once a day before surgery, twice on the day of surgery, and 3 times daily for 2 weeks postoperatively. The prevalence of cystoid macular oedema as detected by fluorescein angiograms was as follows: in the early period (from 1 to 2 postoperative months), cystoid macular oedema developed in $25 \%$ of the indomethacin-treated eyes and in $51 \%$ of the untreated eyes; in the middle period (from 4 to 7 postoperative months), it developed in $11 \%$ of the former group and $21 \%$ in the latter group; in the late period (from 1 to 1.5 postoperative years) it developed in $9 \%$ of the former group and $11 \%$ of the latter group. In both the early and middle periods the difference in prevalence was statistically significant, but in the late period there was no significant difference between the 2 groups. The onset of 'indomethacin-masked cystoid macular oedema' in several treated eyes may account for the insignificant difference in the late period. Prolonged biosynthesis of indomethacin-sensitive materials, including prostaglandins, may be suspected in some aphakic eyes.

There is no conclusive theory as to the aetiology of aphakic cystoid macular oedema. Hypoton;, inflammation, ${ }^{2}$ and vitreous traction $^{3}$ have been regarded as causes. However, causative factors still remain obscure.

Several investigators, including the authors, have pointed out that the occurrence of the disease is in some way related to the synthesis of prostaglandins (PGs) initiated by surgical trauma. ${ }^{4-6}$ Miyake $^{5}$ postulated a hypothesis as follows. The main causative factors of cystoid macular oedema seem to be the release of PGs into the aqueous and other inflammatory mediators derived from a disrupted blood-aqueous barrier. These substances diffuse from the aqueous into the posterior pole of the fundus, where they increase the permeability of the perifoveolar retinal capillary plexus. Based on this hypothetical consideration, Miyake has shown that the incidence of cystoid macular oedema after intracapsular extraction of a senile cataract can be greatly reduced by pre- and postoperative

Correspondence to Dr Kensaku Miyake, Shozankai Medical Foundation, Miyake Eye Hospital, 1070-Kami 5 Higashiozone-Cho, Kita-ku, Nagoya 462, Japan. application of topical indomethacin. ${ }^{57}$ Having measured the amounts of PG-E and PG-F by radioimmunoassay techniques, Miyake et al. ${ }^{8}$ also demonstrated the suppressive effect of topical indomethacin on the synthesis of PGs during lens extraction. These reports originally stressed that indomethacin should be administered pre- and shortly postoperatively because PGs are synthesised most actively during the surgery and shortly after it. Therefore in general this mode of therapy is deemed to be prophylactic. Recently two doubleblind studies were carried out to evaluate indomethacin administered systemically. One study failed to demonstrate the effect in preventing cystoid macular oedema at its usual dosage of $25 \mathrm{mg}$ even given pre- and postoperatively. ${ }^{9}$ and the other noted a decrease in occurrence of the disease with excessively high dosage of $100 \mathrm{mg}$ daily, which was given shortly after the operation..$^{10}$ To date, however, all authors, including ourselves, have investigated the effect of indomethacin only in short-term followup studies.

In the present study the effect of topical indomethacin in preventing cystoid macular oedema was examined and compared with that of a placebo in 
Table 1 Age and sex distribution in the study population

\begin{tabular}{llc}
\hline & Indomethacin group & Control group \\
\hline Age & $65.99 \pm 7 \cdot 22$ & $65.90 \pm 8 \cdot 14$ \\
& & NS by $t$-test \\
Sex & 63 Females/49 males & 59 Females $/ 47$ males \\
& & NS by $\chi^{2}$-test \\
\hline
\end{tabular}

a controlled, double blind, long-term follow-up study. The period of investigation was divided into 3 phases: early (from 1 to 2 postoperative months), middle (from 4 to 7 postoperative months), and late (from 1 to 1.5 postoperative years). This study was undertaken to define the clinical and aetiological significance of topical indomethacin in the treatment of aphakic cystoid macular oedema.

\section{Material and methods}

\section{SUBJECTS}

In the present study a total of 238 eyes underwent intracapsular lens extraction because of senile cataract and were randomly assigned to indomethacin or control group. We excluded the eyes from our study that had surgical accidents such as vitreous loss, rupture of the lens capsule, or endophthalmitis, and had other ocular conditions associated with cystoid macular oedema or other preexisting macular diseases. Finally the study comprised 218 eyes. Fifty-four patients were operated on unilaterally and 81 bilaterally. Sixty-two patients were male and 73 female. They ranged in age from 57 to 92 years, with an average of 65.9 years. There was no statistically significant difference between the 2 groups in sex and age distribution (Table 1).

\section{SURGICAL PROCEDURE}

Surgery was performed by one of the authors (KM), using the same technique throughout. Retrobulbar anaesthesia and akinesia were induced with lignocaine. After a corneoscleral incision had been made with a razor blade the wound was enlarged with Troutman's corneoscleral scissors. Peripheral iridectomy was placed at the 12 o'clock position, and the lens was extracted by a sliding method, by means of a cyropencil and an irisretractor. In no cases was alpha-chymotripsin used, and zonulolysis was performed by gently pressing the scleral wound edge. The wound was closed with five interrupted 10-0 nylon sutures.

MEDICATIONS

Indomethacin powder (obtained from MerckBanyu Co, Tokyo) was dissolved in sesame oil at a concentration of $1 \%$ in slightly modified way as reported by Sawa and Masuda ${ }^{11}$ and sterilised by boiling. For the control group only pure sesame oil sterilised by boiling was used. These 2 solutions were placed in separate vials of the same appearance. All these procedures were performed in the pharmacy of the hospital under the guidance of the controller (KM) of the study, who had access to the randomisation code. The solutions were given to the patients by one of the authors (HM) without knowledge of their components. Informed consent had been previously obtained from all the patients.

Indomethacin drops were instilled once the day before surgery, twice on the day of surgery ( 3 hours and 1 hour preoperatively), and 3 times daily for 2 weeks postoperatively. ${ }^{8}$ Pre- and postoperative medications, that is, local corticosteroids and systemic and local antibiotics, were given in a routine manner.

Pure sesame oil, together with routine medications, was administered to the control group in the same way.

\section{DETECTION OF CYSTOID MACULAR \\ OEDEMA}

Fluorescein angiography was performed at each of the 3 stages of the investigation (early, from 1 to 2 months postoperatively; middle, from 4 to 7 months postoperatively; and late, from 1 to 1.5 years postoperatively). Some patients were unable for social or psychological reasons to attend all 3 angiography sessions. The severity of cystoid macular oedema was graded into 4 classes on the basis of fluorescein angiograms, biomicroscopic appearance, fundus drawings, visual acuity, and visual field. Details of the grading system were given previously ${ }^{5}$ and only brief remarks are made here.

Grade 0 has no symptoms and shows no trace of changes on the fluorescein angiogram. Grade $I$ is the subclinical group in which slight fluorescein retention is seen on the angiogram, and the area of the retention is less than or equal to $1 \mathrm{~mm}^{2}$. The lesion does not show a complete circle round the fovea. No abnormality can be detected by ophthalmoscopy or slit-lamp microscopy. Grade II is the group with objective symptoms, and the fluorescein angiogram shows the dye retention in the macular area forming a complete circle in stellate or flower petal pattern. The diameter of the lesion is less than $2 \mathrm{~mm}(4 / 3$ disc diameter), that is, the area of the lesion is less than or equal to $3 \cdot 14 \mathrm{~mm}^{2}$ but larger than $1 \mathrm{~mm}^{2}$. On ophthalmoscopy no marked changes can be seen, but biomicroscopy often reveals the presence of cystic oedema. No marked functional deterioration can be found in the visual. 
Table 2 Prevalence and severity of cystoid macular oedema in indomethacin-treated and untreated eyes

\begin{tabular}{|c|c|c|c|c|c|c|c|c|c|c|}
\hline \multirow{3}{*}{$\begin{array}{l}\text { Follow-up } \\
\text { postoperative period }\end{array}$} & \multicolumn{10}{|c|}{ Severity of diseases $\quad$ No. of eyes $(\%)$} \\
\hline & \multicolumn{5}{|c|}{ Indomethacin group } & \multicolumn{5}{|c|}{ Control group } \\
\hline & 0 & $I$ & $I I$ & $I I I$ & Total & 0 & $I$ & $I I$ & $I I I$ & Total \\
\hline $\begin{array}{l}\text { Early } \\
\text { (1st-2nd mo.) }\end{array}$ & $\begin{array}{l}84 \\
(75 \%)\end{array}$ & $\begin{array}{l}21 \\
(19 \%)\end{array}$ & $\begin{array}{l}7 \\
(6 \%)\end{array}$ & $\begin{array}{l}0 \\
(0 \%)\end{array}$ & $\begin{array}{l}112 \\
(100 \%)\end{array}$ & $\begin{array}{l}52 \\
(49 \%)\end{array}$ & $\begin{array}{l}34 \\
(32 \%)\end{array}$ & $\begin{array}{l}18 \\
(17 \%)\end{array}$ & $\begin{array}{l}2 \\
(2 \%)\end{array}$ & $\begin{array}{l}106 \\
(100 \%)\end{array}$ \\
\hline $\begin{array}{l}\text { Middle } \\
\text { (4th-7th mo.) }\end{array}$ & $\begin{array}{l}83 \\
(89 \%)\end{array}$ & $\begin{array}{l}7 \\
(8 \%)\end{array}$ & $\begin{array}{l}2 \\
(2 \%)\end{array}$ & $\begin{array}{l}1 \\
(1 \%)\end{array}$ & $\begin{array}{l}93 \\
(100 \%)\end{array}$ & $\begin{array}{l}74 \\
(79 \%)\end{array}$ & $\begin{array}{l}15 \\
(16 \%)\end{array}$ & $\begin{array}{l}4 \\
(4 \%)\end{array}$ & $\begin{array}{l}1 \\
(1 \%)\end{array}$ & $\begin{array}{l}94 \\
(100 \%)\end{array}$ \\
\hline $\begin{array}{l}\text { Late } \\
\text { (12th-18th mo.) }\end{array}$ & $\begin{array}{l}80 \\
(91 \%)\end{array}$ & $\begin{array}{l}6 \\
(7 \%)\end{array}$ & $\begin{array}{l}2 \\
(2 \%)\end{array}$ & $\begin{array}{l}0 \\
(0 \%)\end{array}$ & $\begin{array}{l}88 \\
(100 \%)\end{array}$ & $\begin{array}{l}80 \\
(89 \%)\end{array}$ & $\begin{array}{l}6 \\
(7 \%)\end{array}$ & $\begin{array}{l}4 \\
(4 \%)\end{array}$ & $\begin{array}{l}0 \\
(0 \%)\end{array}$ & $\begin{array}{l}90 \\
(100 \%)\end{array}$ \\
\hline
\end{tabular}

acuity and the visual field. Grade III is the group with subjective symptoms, and in many cases attenuation of the visual acuity and central relative scotoma can be demonstrated. Fluorescein angiography shows fluorescein retention of a circular pattern with a diameter larger than $2 \mathrm{~mm}$, that is, an area larger than $3.14 \mathrm{~mm}^{2}$. Definite changes of the macular area can be seen by biomicroscopy and ophthalmoscopy. These changes may persist and lead to permanent disturbance.

An ophthalmic photographer and one of the authors (SS), who had no knowledge of the medications given, evaluated the severity of the disease.

\section{Results}

The prevalence and the severity of cystoid macular oedema, in both the indomethacin-treated and placebo groups, is shown in the Table 2 . In the early period after surgery dye leakage was found in $51 \%$ of the control group and in $25 \%$ of the indomethacin group. The difference is statistically highly significant $\left(x^{2}\right.$ test, $\left.P<0.005\right)$. In the middle period dye leakage was found in $21 \%$ of cases in the control group and in $11 \%$ of the treated group. The difference is statistically significant $\left(x^{2}\right.$ test, $\mathbf{P}<0.005$ ). During the middle period the prevalence of leakage decreased in both groups compared with the early period. During the late period the prevalence decreased further in both groups: dye leakage was found in $9 \%$ of cases in the indomethacin group and in $11 \%$ of cases in the control group. This difference is not statistically significant ( $x^{2}$ test, $0.05<\mathbf{P}<0.25$ ).

Gradual decreases in macular leakage were recognised in the indomethacin group as well as in the control group, which agrees with the natural course of the disorder. The fact that the difference in prevalence of macular leakage between the treated and untreated eyes became statistically insignificant during the late postoperative phase is in part ascribed to the late onset of macular leakage in several indomethacin-treated eyes. Among 8 treated eyes that showed macular leakage during the late phase 4 had late-onset macular leakage. On the other hand among 10 eyes of the control group that showed macular leakage during the late postoperative period none had late onset and 3 had middle onset. One case is reported here.

\section{CASE REPORT}

A 64-year-old woman with senile cataract underwent intracapsular lens extraction without pre- or postoperative complications. By the method described above indomethacin was given together with other usual medications. In fluorescein angiograms done 1.5 and 7 months postoperatively there was no trace of dye leakage in the macular area (Figs. 1 and 2). This eye had a visual acuity of 1.2 at both angiography sessions. In the 13 th postoperative month

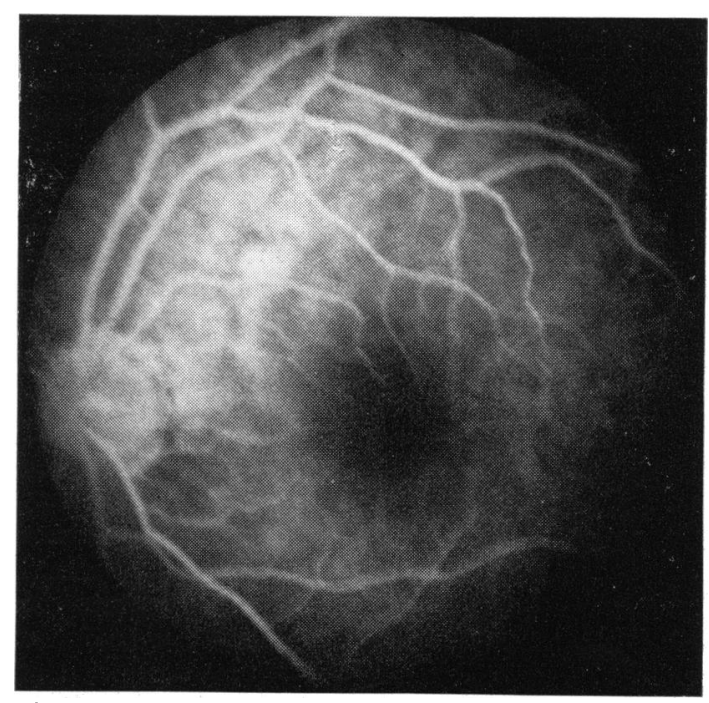

Fig. 1 Fluorescein angiogram of the reported case taken 1.5 months postoperatively. No trace of dye leakage is seen in the macular area 
the patient complained of blurred vision. Fluorescein angiograms taken at that time revealed cystoid macular oedema of grade II (Fig. 3). Visual acuity at that time was $0 \cdot 8$.

When we evaluated the postoperative visual acuity, we excluded 15 eyes and 10 eyes from the indomethacin group and the control group respec-

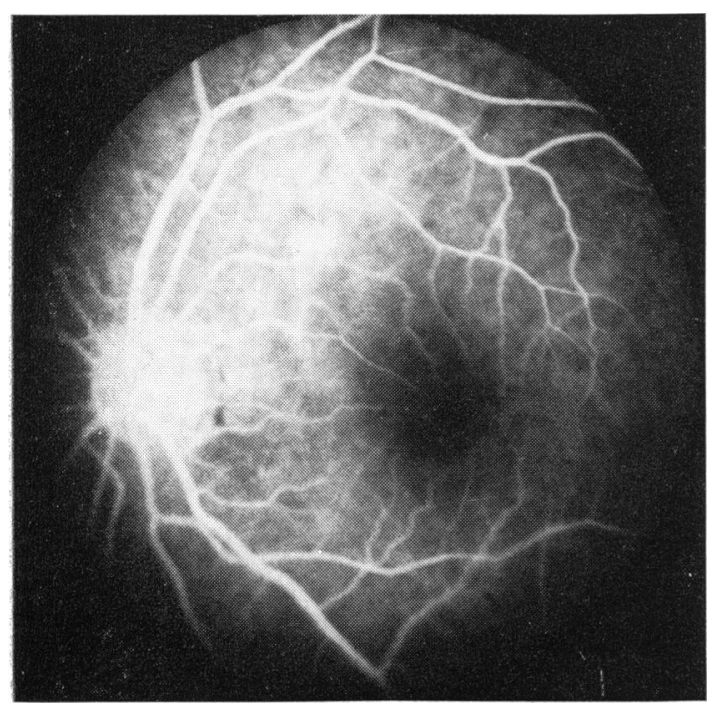

Fig. 2 Fluorescein angiogram of the reported case taken 7 months postoperatively. No trace of dye leakage is seen

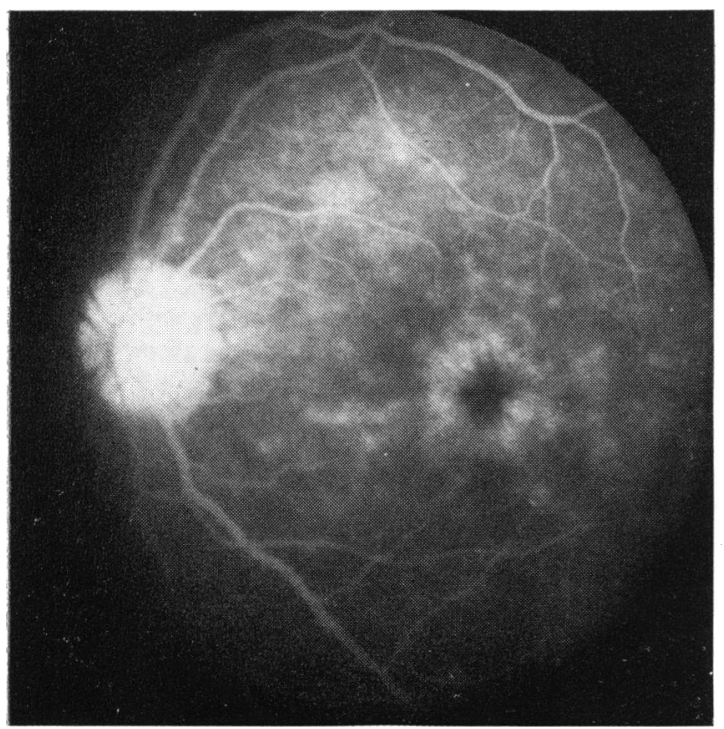

Fig. 3 Fluorescein angiogram of the reported case taken 13 months postoperatively. Note cystoid macular oedema of grade II
Table 3 Visual results

\begin{tabular}{|c|c|c|c|c|}
\hline & \multicolumn{4}{|c|}{ Distributions of vision No. of eyes (\%) } \\
\hline & \multicolumn{2}{|c|}{ Indomethacin group } & \multicolumn{2}{|c|}{ Control group } \\
\hline & $1 \cdot 0-0 \cdot 6$ & $0.5 \downarrow$ & $1 \cdot 0-0 \cdot 6$ & $0 \cdot 5 \downarrow$ \\
\hline $\begin{array}{l}\text { Early period } \\
\text { (1st-2nd mo.) }\end{array}$ & $\begin{array}{l}94 \\
(98)\end{array}$ & $\begin{array}{l}3 \\
(2)\end{array}$ & $\begin{array}{l}85 \\
(89)\end{array}$ & $\begin{array}{l}11 \\
(11)\end{array}$ \\
\hline $\begin{array}{l}\text { Middle period } \\
\text { (4th-7th mo.) }\end{array}$ & $\begin{array}{l}82 \\
(99)\end{array}$ & $\begin{array}{l}1 \\
(1)\end{array}$ & $\begin{array}{l}87 \\
(98)\end{array}$ & $\begin{array}{l}2 \\
(2)\end{array}$ \\
\hline $\begin{array}{l}\text { Late period } \\
\text { (12th-18th mo.) }\end{array}$ & $\begin{array}{l}82 \\
(100)\end{array}$ & $\begin{array}{l}0 \\
(0)\end{array}$ & $\begin{array}{l}82 \\
(99)\end{array}$ & $\begin{array}{l}1 \\
(1)\end{array}$ \\
\hline
\end{tabular}

tively. These eyes had optic disc atrophy, and a suspicion of amblyopia; also it was impossible to determine the exact visual acuity of these patients because of their poor health and low intelligence. In each postoperative period the distribution of visual acuity in the indomethacin group was significantly better than that in the control group $(P<0.05)$. In the other 2 periods there were no significant differences between the 2 groups.

\section{Discussion}

In the present study the natural course of cystoid macular oedema was compared in eyes treated with indomethacin and in untreated eyes following intracapsular cataract extractions. In the control group the incidence of the disease in the early postoperative period was $51 \%$, and it decreased to $11 \%$ by the late postoperative period $(4 \%$ of clinical cystoid macular oedema). This rate of incidence agrees with that reported by others. ${ }^{12-14}$ However, the incidence of cystoid macular oedema during the early postoperative period was less in this study than in previous studies. ${ }^{5} 7$

In both the indomethacin-treated and the untreated eyes this disorder was found to show a similar self-limiting tendency, that is, a high incidence during the early postoperative period and a gradual decrease thereafter.

The present study reconfirmed the finding that topical indomethacin reduced the occurrence of cystoid macular oedema during the early postoperative period. This study also demonstrated the prophylactic effect of indomethacin during the middle period. Furthermore, these findings suggest that the onset of cystoid macular oedema during the early and middle postoperative periods is closely related to the presence of indomethacinsensitive substances (prostaglandins, for example) which are biosynthesised during the surgical procedure. Conversely, during the late postoperative period there was no difference in the incidence of 
cystoid macular oedema between the 2 groups. One of the reasons for the low incidence of the disease during the late postoperative period is mathematical chance and another reason is the possibility of 'indomethacin-masked cystoid macular oedema', as shown by the case report. Such was the case in 4 of 8 eyes that had macular leakage during the late postoperative period. The number of cases of indomethacin-masked cystoid macular oedema was such that no significant difference was found between the 2 groups during the late postoperative period. In these eyes, which were aphakic, the synthesis of small amounts of indomethacinsensitive substances (probably prostaglandins) may be abnormally prolonged.

In a case previously described ${ }^{17}$ cystoid macular oedema appearing 3 months after cataract surgery subsided on the application of indomethacin for 1 week and recurred when indomethacin therapy was withheld.

In some cases, elevated levels of prostaglandins $E$ and $F$ were observed not only during surgery but also after it. ${ }^{8}$ These phenomena, together with the results of the present study, indicate the abnormal condition of biosynthesis and extraocular removal of indomethacin-sensitive materials in aphakic eyes. The factors that influence this condition remain to be investigated. It has not been clearly shown which substances are sensitive to indomethacin. Among possible candidates are aqueous biotoxic complex (ABC factor) ${ }^{15}$ histamine, bradykinin, and 5-hydroxytryptamine. ${ }^{16}$ In view of previous investigations ${ }^{5}>817$ we strongly suspect that prostaglandins are uniquely susceptible to the effects of indomethacin.

\section{References}

'Duke-Elder S. In: System of Ophthalmology. London: Kimpton, 1971: 20: 213.

${ }^{2}$ Gass JMD, Norton EWD. Fluorescein studies of patients with macular edema and papilloedema following cataract extraction. Trans Am Ophthalmol Soc 1966; 64: 232-49.

${ }^{3}$ Irvine SR. Newly defined vitreous syndrome following cataract surgery. Am J Ophthalmol 1953; 36: 599-619.

${ }^{4}$ Tennant JL. Is cystoid macular edema reversible by oral Indocin, yes or no? In: Emery JM, Paton D, eds. Current Concepts in Cataract Surgery: Selected Proceedings of the Fourth Biennial Cataract Surgical Congress. St Louis: Mosby, 1976: 310-1.

${ }^{5}$ Miyake K. Prevention of cystoid macular edema after lens extraction by topical indomethacin (I) A preliminary report. Albrecht von Graefes Arch Klin Ophthalmol 1977; 203: 81-8.

${ }^{6}$ Yannuzzi LA, Klein RM, Wallyn RH, Cohen N, Katz I. Ineffectiveness of indomethacin in treatment of chronic cystoid macular edema. Am J Ophthalmol 1977; 84: 517-9. ${ }^{7}$ Miyake K. Prevention of cystoid macular edema after lens extraction by topical indomethacin (II) A control study in bilateral extractions. Jpn J Ophthalmol 1978, 22: 80-94.

${ }^{8}$ Miyake K, Sugiyama S, Norimatsu I, Ozawa T. Prevention of cystoid macular edema after lens extraction by topical indomethacin (III) Radioimmunoassay measurement of prostaglandins in the aqueous during and after lens extracton procedures. Albrecht von Graefes Arch Klin Ophthalmol 1978; 209 : 83-8.

${ }^{9}$ Sholiton DB, Reinhart WJ, Frank KE. Indomethacin as a means of preventing cystoid macular edema following cataract extraction. Am Intra-Ocular Implant Soc J 1979; 5: $137-40$.

${ }^{10}$ Klein RM, Katzin HM, Yannuzzi LA. The effect of indomethacin pretreatment of aphakic cystoid macular edema. Am J Ophthalmol 1979; 87: 487-9.

${ }^{11}$ Sawa M, Masuda K. Topical indomethacin in soft cataract aspiration. Jpn J Ophthalmol 1976; 20: 514-9.

${ }^{12}$ Gass JMD, Norton EWD. Follow-up study of cystoid macular edema following cataract extraction. Trans Am Acad Ophthaimol Otolaryngol 1969; 73: 665-82.

${ }^{13}$ Hitchings RA. Aphakic macular oedema: a two-year follow-up study. Br J Ophthalmol 1977; 61: 628-30.

${ }^{14}$ Yamamoto R, Kimura Y, Ozaki R, et al. Cystoid macular edema after cataract extraction. Jpn Clin J Ophthalmol 1979; 33: 267-9.

${ }^{15}$ Worst JGF. Biotoxität des Kammerwassers. Klin Monatsbl Augenheilkd 1975; 167: 376-84.

${ }^{16}$ Easty D, Dallas N, O'Malley R. Aphakic macular oedema following prosthetic lens implantation. Br J Ophthalmol 1977; 61 : 321-6.

${ }^{17}$ Miyake K, Sakamura S, Miura H. Prostaglandins as a causative factor of cystoid macular edema after lens extraction. III. Jpn Clin J Ophthalmol 1978; 32: 217-22. 